\title{
Effect of supplementation of yeast with bacteriocin and Lactobacillus culture on growth performance, cecal fermentation, microbiota composition, and blood characteristics in broiler chickens
}

\author{
C. Y. Chen ${ }^{1}$, S. W. Chen ${ }^{1}$, and H. T. Wang ${ }^{2, *}$
}

* Corresponding Author: H. T. Wang Tel: +886-228610511 ext.31232, Fax: +886228613100, E-mail: rumen0808@gmail.com

'Department of Animal Science and Technology, National Taiwan University, Taipei 10617, Taiwan 2 Department of Animal Science, Chinese Culture University, Taipei 11114, Taiwan

Submitted Mar 10, 2016; Revised May 9, 2016: Accepted Jun 1, 2016
Objective: The aim of the present study was to investigate the effect of yeast with bacteriocin and Lactobacillus cultures (mixture of Lactobacillus agilis BCRC 10436 and Lactobacillus reuteri $\mathrm{BCRC} 17476$ ) supplements, alone or in combination, on broiler chicken performance. Methods: A total of 300,1-d-old healthy broiler chickens were randomly divided into five treatment groups: i) basal diet (control), ii) basal diet $+0.25 \%$ yeast (Saccharomyces cerevisiae) (YC), iii) basal diet $+0.25 \%$ yeast with bacteriocin (BA), iv) basal diet + Lactobacillus cultures $(\mathrm{LAB})$, and $\mathrm{v}$ ) basal diet $+0.25 \%$ yeast with bacteriocin + Lactobacillus cultures (BA+LAB). Growth performance, cecal microbiota, cecal fermentation products, and blood biochemistry parameters were determined when chickens were 21 and $35 \mathrm{~d}$ old.

Results: The supplementation of $\mathrm{YC}, \mathrm{BA}$, and $\mathrm{BA}+\mathrm{LAB}$ resulted in a significantly better feed conversion rate (FCR) than that of the control group during 1 to $21 \mathrm{~d}(\mathrm{p}<0.05)$. The LAB supplementation had a significant effect on the presence of Lactobacillus in the ceca at $35 \mathrm{~d}$. None of the supplements had an effect on relative numbers of L. agilis and L. reuter at $21 \mathrm{~d}$, but the BA supplementation resulted in the decrease of both Lactobacillus strains at $35 \mathrm{~d}$. The BA+LAB supplementation resulted in higher short chain fatty acid (SCFA) in the ceca, but LAB supplementation significantly decreased the SCFA at $35 \mathrm{~d}(\mathrm{p}<0.05)$. All treatments tended to decrease ammonia concentration in the ceca at $21 \mathrm{~d}$, especially in the LAB treatment group. The BA supplementation alone decreased the triacylglycerol (TG) concentration significantly at $21 \mathrm{~d}(\mathrm{p}<0.05)$, but the synergistic effect of BA and LAB supplementation was required to reduce the TG concentration at $35 \mathrm{~d}$. The YC supplementation tended to increase the plasma cholesterol at $21 \mathrm{~d}$ and $35 \mathrm{~d}$. However, the BA supplementation significantly decreased the cholesterol and low density lipoprotein cholesterol level at 35 d. In conclusion, the BA+LAB supplementation was beneficial to body weight gain and FCR of broiler chickens.

Conclusion: The effect of BA and LAB supplementation may be a result of the growth of lactic acid bacteria enhancement and physiological characterization of bacteriocin, and it suggests that the BA and LAB supplementation level or Lactobacillus strain selection should be integrated in future supplementation designs.

Keywords: Broiler, Growth Performance, Bacteriocin, Lactic Acid Bacteria, Cecal Fermentation

\section{INTRODUCTION}

Antibiotics have been widely used as feed additives for broiler chickens, owing to their ability to manipulate the intestinal microbial population, improve feed conversion rate (FCR), and promote growth. However, there is growing concern regarding the possible antibiotic residue 
effects and the development of drug resistant bacteria attributed to the continuous feeding of antibiotics at sub-therapeutic levels. Previous studies have indicated that probiotics enhanced the immune system, increased body weight gain (BWG), reduced diarrhea, and improved FCR [1]. Kalavathy et al [2] found an improvement in BWG and FCR of broiler chickens fed a mixture of different Lactobacillus strains from one to $42 \mathrm{~d}$ of age. A consistent improvement in the growth performance of chickens fed a culture of Lactobacillus has also been reported [3].

Previous studies indicated that a mixed Lactobacillus culture comprising $L$. agilis and $L$. salivarius had a beneficial effect on performance and immune function in broiler chicken [3]. There are three predominant species of Lactobacillus in the chicken digastric tract (L. reuteri, L. salivarius, and L. animalis), but only $L$. reuteri can produce reuterin, an intermediary metabolite of glycerol with antibacterial activity [4]. Feeding diets containing $L$. reuteri enhanced the production of anti-salmonella IgM antibodies and function of T-cells in newly hatched chicks and pullets, and longer villi were found in the ileum of chickens and turkeys treated with $L$. reuteri. The importance of $L$. reuteri as a competitive exclusion agent has been investigated by Edens et al [5]. Dobrogosz et al [6] also proposed that $L$. reuteri plays a modulating role in the growth of all enteric microflora through its in vivo ability to produce reuterin. Two possible mechanisms for the beneficial effects of lactic acid bacteria on gastrointestinal disturbances are: i) production of antimicrobial compounds such as lactic acid and bacteriocins, and ii) adherence to the mucosa and co-aggregation to form a barrier that prevents colonization by pathogens. However, the investigation of the Lactobacillus strain characteristics indicated that the potential cell surface adhesion ability was present in L. reuteri but not in L. agilis [7].

Albusin B, a class III bacteriocin produced by Ruminococcus albus, is a $32-\mathrm{kDa}$ protein with relatively hydrophilic content that has moderate specificity against some ruminal bacterial species. We have previously established Saccharomyces cerevisiae as a stable and safe expression system for the mass production of albusin B [8]. A previous study also suggested that yeast with albusin $B$ inhibits pathogenic bacteria, increases intestinal absorption of protein and glucose, and improves gut barrier function. Furthermore, it also modulated the gut microbiota by increasing cecal Lactobacillus counts and decreasing pathogenic populations [9]. Results of the effect of feeding with Lactobacillus cultures and zinc bacitracin alone, or in combination, on the growth of broiler chickens suggested that food conversion was reduced by zinc bacitracin alone but was improved by the combined use of Lactobacillus cultures and bacitracin [10].

In spite of these reports, there is limited information on the function and benefit of the combined supplementation of Lactobacillus cultures and bacteriocin product. Therefore, the present study was conducted to investigate the effect of sup- plementation of bacteriocin product (yeast with bacteriocin) and Lactobacillus cultures, alone or in combination, on the growth performance of broiler chickens. The cecal fermentation parameters and the adhesion ability of lactic acid bacteria were also determined to assess the possible mechanisms of different supplementations.

\section{MATERIAL AND METHODS}

\section{Animal treatments and experimental design}

All animal care procedures in this study were approved by the Institutional Animal Care and Use Committee of the Chinese Culture University. Three hundred 1-d-old healthy Arbor Acres broiler chickens (mixed sex) were used in a completely randomized design (CRD) experiment. They were fed with corn-soybean meal basal diets, which were formulated to meet the recommendations of the National Research Council [11] (Table 1). The broiler chickens were randomly divided into five groups: i) basal diet (control), ii) basal diet $+0.25 \%$ yeast (Saccharomyces cerevisiae) (YC), iii) basal diet $+0.25 \%$ yeast with bacteriocin (BA), iv) basal diet+Lactobacillus cultures (LAB), and v) basal diet $+0.25 \%$ yeast with bacteriocin + Lactobacillus cultures (BA+LAB). Each treatment consisted of three replicate pens with 20 chickens per pen. Continuous lighting and access to feed

Table 1. Composition of the basal diet fed to broiler chickens

\begin{tabular}{lcc}
\hline Items & 0 to $21 \mathbf{d}$ & 22 to $35 \mathbf{d}$ \\
\hline Ingredients (\%) & & \\
Yellow corn, grain & 48.42 & 57.09 \\
Soybean meal, 44\% & 34.85 & 29.55 \\
Fish meal, 65\% & 4.96 & 2.80 \\
Soybean oil & 7.75 & 6.45 \\
Dicalcium phosphate & 1.10 & 1.38 \\
Calcium carbonate & 1.30 & 1.31 \\
DL-methionine & 0.30 & 0.32 \\
Choline-CL50 & 0.07 & 0.05 \\
Vitamin premix) & 0.30 & 0.30 \\
Mineral premix & 0.20 & 0.20 \\
Salts & 0.20 & 0.30 \\
Cellulose & 0.50 & 0.25 \\
Total & 0.25 & 100 \\
Calculated analysis & 100 & \\
Crude protein (\%) & & 20.02 \\
ME (kcal/kg) & 23.00 & 3,201 \\
Lysine (\%) & 3,201 & 1.11 \\
Methionine+Cystine (\%) & 1.35 & 0.91 \\
Calcium (\%) & 0.92 & 1.00 \\
Available phosphorus (\%) & 1.03 & 0.45 \\
\hline
\end{tabular}

$\mathrm{ME}$, metabolizable energy.

1) Vitamin premix supplied per kilogram of diet: vitamin $A, 12,000 \mathrm{IU}$; vitamin $D_{3}, 3,125$ ICU; vitamin E, $37.5 \mathrm{IU}$; vitamin $\mathrm{K}_{3}, 6.25 \mathrm{mg}$; vitamin $\mathrm{B}_{1}, 3.75 \mathrm{mg}$; vitamin $\mathrm{B}_{2}, 12.5 \mathrm{mg}$; vitamin $\mathrm{B}_{6}, 10.0 \mathrm{mg}$; Ca-pantothenate, $18.8 \mathrm{mg}$; niacin, $50 \mathrm{mg}$; biotin, $0.06 \mathrm{mg}$; folic acid, $1.25 \mathrm{mg}$; vitamin $B_{12}, 0.05 \mathrm{mg}$.

${ }^{2)}$ Mineral premix supplied per kilogram of diet: $\mathrm{Cu}\left(\mathrm{CuSO}_{4} \cdot 5 \mathrm{H}_{2} \mathrm{O}, 25.45 \% \mathrm{Cu}\right), 6 \mathrm{mg}$; $\mathrm{Fe}\left(\mathrm{FeSO}_{4} \cdot 7 \mathrm{H}_{2} \mathrm{O}, 20.09 \% \mathrm{Fe}\right), 50 \mathrm{mg} ; \mathrm{Mn}\left(\mathrm{MnSO}_{4} \cdot \mathrm{H}_{2} \mathrm{O}, 32.49 \% \mathrm{Mn}\right), 40 \mathrm{mg} ; \mathrm{Zn}(\mathrm{ZnO}$, $80.35 \% \mathrm{Zn}), 60 \mathrm{mg}$; Se $\left(\mathrm{NaSeO}_{3}, 45.56 \% \mathrm{Se}\right), 0.075 \mathrm{mg}$. 
and water was provided throughout the experiment. The house temperature was maintained between $32^{\circ} \mathrm{C}$ and $35^{\circ} \mathrm{C}$ at the first week and decreased $2^{\circ} \mathrm{C}$ per week in the following experiment period. Ventilation was regulated by thermostat-controlled circulating and exhaust fans. The total feed intake for each replicate was measured during the test experiment period. The FCR was calculated as gram of feed consumed of per gram body weight gained.

\section{Preparation of yeast with bacteriocin}

Cloning of the structural gene and plasmid construction for expression in S. cerevisiae and mass production of bacteriocinexpressing yeast were conducted as described by Wang et al [8]. The albB gene (NCBI: AF469209) of albusin B from R. albus 7 was applied for expression in S. cerevisiae DBY 747 as a bacteriocin source. The albusin B-expressing yeast was massproduced in yeast extract peptone dextrose medium at $\mathrm{pH} 5.0$ and $30^{\circ} \mathrm{C}$. After $48 \mathrm{~h}$ of fed-batch fermentation, the yeast products were recovered by centrifugation, followed by spray drying for future use. The dried yeast contained $1 \mathrm{mg}$ bacteriocin protein per gram of yeast product.

\section{Lactobacillus culture preparation}

Two strains of Lactobacillus (L. agilis BCRC 10436 and L. reuteri BCRC 17476) isolated from chicken intestine and obtained from the Bioresource Collection and Research Center (Hsinchu, Taiwan), were used in this study. Two strains were inoculated separately into Man, Rogosa, and Sharpe (MRS) broth (Oxoid, Basingstoke, UK) and incubated at $39^{\circ} \mathrm{C}$ for $16 \mathrm{~h}$, after which the bacterial cells were harvested by centrifugation at 3,000 $\times g$ for $20 \mathrm{~min}$ at $4^{\circ} \mathrm{C}$. The bacterial pellets were lyophilized for 48 $\mathrm{h}$ and stored at $4^{\circ} \mathrm{C}$. To obtain a concentration of $107 \mathrm{CFU}$ per gram diet, the lyophilized cell pellet of each strain (LAB) was diluted with appropriate amounts of cornstarch and skimmed milk powder, based on original colony forming units per gram determined on MRS agar plate of each strain. The LAB was stored at $4^{\circ} \mathrm{C}$ and mixed into the feed daily to ensure viable bacterial cells in the feed during the experimental period. The viability of the bacterial cells of each strain was checked weekly by MRS agar to ensure that the concentration of the viable bacterial cells remained at $107 \mathrm{CFU}$ per gram diet.

\section{Cecal microbial population and identification of supplement lactic acid bacteria}

Cecal samples for microbial population determination were collected individually on $21 \mathrm{~d}$ and $35 \mathrm{~d}$ from the fresh caeca of 18 chickens/treatment (six chickens per replicate). Approximately $1 \mathrm{~g}$ of fresh cecal content was weighed and transferred, within $2 \mathrm{~min}$ of extraction, to $9 \mathrm{~mL}$ of pre-reduced sterile dilution blank solution. It was then homogenized for $1 \mathrm{~min}$ before series dilution. The cecal microbial populations were determined by serial dilution $\left(10^{-4}\right.$ to $\left.10^{-7}\right)$ of cecal samples in anaerobic diluents before inoculation onto Petri dishes of sterile agar. The plate media used were Wilkins-Chalgren agar (Oxoid CM 0619, Basingstoke, UK) for total anaerobic bacteria, Rogosa SL agar (Difco 248020, Sparks, MD, USA) for lactobacilli, and $\mathrm{m}$-EI agar (Difco 214881) for enterococci. Inoculated agar plates were incubated anaerobically $\left(97 \% \mathrm{CO}_{2}, 3 \% \mathrm{H}_{2}\right)$ at $39^{\circ} \mathrm{C}$. The contents of all plates were counted between 24 and $48 \mathrm{~h}$ after inoculation. Identification of $L$. agilis and $L$. reuteri was carried out according to [3], using the sugar test inoculation. Sugar fermentation patterns were examined using a semiautomatic system for bacterial identification.

\section{Short chain fatty acid composition and ammonia concentration assay}

Approximately $0.5 \mathrm{~g}$ of each sample of fresh cecal content collected at microbial population determination section was suspended in $2 \mathrm{~mL}$ of pre-cooled (at $4^{\circ} \mathrm{C}$ ) sterile milli-Q water. Subsequently, samples were centrifuged at $18,500 \times \mathrm{g}$ for $15 \mathrm{~min}$, and the supernatant was stored at $-80^{\circ} \mathrm{C}$ for short chain fatty acid (SCFA) analysis. SCFA concentration was determined by gas chromatography. The analysis was conducted with a Perkin Elmer Clarus 500 (PerkinElmer Inc., Waltham, MA, USA) and separated by Nukol Capillary Gas Chromatograph Column (Supelco, Bellefonte, PA, USA). Each sample peak profile was integrated and quantified relative to an internal standard of methylbutyric acid placed in the same sample. The cecal ammonia concentration was measured using an ammonia assay kit (Product code AA0100, Sigma, St. Louis, MO, USA).

\section{Blood biochemical parameter assay}

Blood samples of 15 broiler chickens randomly selected from each dietary treatment ( 5 chickens per pen) were collected from the wing vein at 3 and 5 wks of age for biochemical parameter assay. Heparin was used as an anticoagulant, and plasma samples were obtained by centrifugation at $860 \times \mathrm{g}$ for $20 \mathrm{~min}$ and stored at $-80^{\circ} \mathrm{C}$. Stored plasma samples were analyzed for aspartate aminotransferase (AST), alanine aminotransferase (ALT), total cholesterol (CHOL), low density lipoprotein-cholesterol (LDL-C), and triacylglycerol (TG) using analytical kits according to the manufacturer's instructions (Fortress Diagnostics, Antrim, UK).

\section{Microbial adhesion to hydrocarbons assay}

The microbial adhesion to hydrocarbons (MATH) was determined using xylene. Approximately $1 \mathrm{~g}$ of fresh cecal or ileum content was weighed and transferred to $9 \mathrm{~mL}$ of pre-reduced sterile dilution blank solution and serial diluted to $10^{-3}$ as inoculation sample. The $1 \mathrm{~mL}$ inoculation sample was added to $9 \mathrm{~mL}$ MRS broth and incubated for $16 \mathrm{~h}$ at $39^{\circ} \mathrm{C}$. Two milliliters of bacterial suspension were put in contact with $0.4 \mathrm{~mL}$ of xylene by vortexing for $120 \mathrm{~s}$. The phases were allowed to separate by decantation. The aqueous phase was carefully removed, 
and the $A_{600}$ was measured. The decrease in the absorbance of the aqueous phase was taken as a measure of the cell surface hydrophobicity $(H \%)$, which was calculated with the formula $H \%=([A o-A] / A o) \times 100$, where $A o$ and $A$ are the absorbance before and after extraction with xylene.

\section{Statistical analysis}

Data were analyzed in a CRD using the general linear models procedures of SAS [12]. The microbial population, SCFA, ammonia, and blood biochemical parameters were analyzed on individual broiler chickens whereas growth performance was based on cage weights. Feed to gain ratio was calculated and analyzed on a cage basis. Differences among treatments were assessed by analysis of variance followed by a Duncan's test, with a significance level of $\mathrm{p}<0.05$.

\section{RESULTS}

\section{Growth performance}

The data for BWG and FCR are presented in Table 2. Dietary supplementation by $\mathrm{BA}+\mathrm{LAB}$ leads to greater BWG than the control diet in broiler chickens during 22 to $35 \mathrm{~d}$. None of the treatments had a significant effect on BWG during 1 to $21 \mathrm{~d}$. However, during the overall feeding period, $\mathrm{BA}+\mathrm{LAB}$ supplementation resulted in better BWG. Except for LAB supplementation, other supplementations resulting in a significantly better FCR compared to the control group during 1 to $21 \mathrm{~d}$.

\section{Cecal microbial population}

The results of the cecal bacterial population analysis are shown in Table 3. Compared to the YC group, the viable count of total anaerobes was lower in 21-d-old broiler chickens fed with the control diet or BA supplementation, but no significant differ-
Table 3. Effect of yeast with bacteriocin (BA), Lactobacillus cultures (LAB) and mixture of both supplementations on cecal content bacterial populations of broiler chickens

\begin{tabular}{lccc}
\hline \multirow{2}{*}{ Treatment $^{1)}$} & \multicolumn{3}{c}{ Bacterial populations (log cfu/g) } \\
\cline { 2 - 4 } & Lactobacillus & Enterococcus & Total anaerobe \\
\hline $21 \mathrm{~d}$ & & & \\
Control & 7.82 & 5.68 & $8.61^{\mathrm{b}}$ \\
YC & 7.86 & 5.86 & $9.42^{\mathrm{a}}$ \\
BA & 7.49 & 5.77 & $8.42^{\mathrm{b}}$ \\
LAB & 7.97 & 5.97 & $9.01^{\mathrm{ab}}$ \\
BA+LAB & 7.85 & 5.85 & $8.82^{\mathrm{ab}}$ \\
SEM & 0.290 & 0.335 & 0.242 \\
p-value & 0.346 & 0.579 & 0.043 \\
35 d & & & \\
Control & $7.17^{\mathrm{b}}$ & 5.49 & 7.94 \\
YC & $6.71^{\mathrm{b}}$ & 5.71 & 7.97 \\
BA & $7.28^{\mathrm{ab}}$ & 5.41 & 8.19 \\
LAB & $7.87^{\mathrm{a}}$ & 5.68 & 8.45 \\
BA+LAB & $7.25^{\mathrm{ab}}$ & 5.34 & 8.14 \\
SEM & 0.219 & 0.582 & 0.180 \\
p-value & 0.032 & 0.441 & 0.154 \\
\hline
\end{tabular}

${ }^{1)}$ Control, basal diet; $Y C$, yeast control (basal diet $+0.25 \%$ Saccharomyces cerevisiae yeast powder); $B A$, basal diet $+0.25 \%$ yeast with bacteriocin; $L A B$, basal diet+Lactobacillus cultures; $B A+L A B$, basal diet $+0.25 \%$ yeast with bacteriocin+Lactobacillus cultures.

a,b Means with different superscripts with in the same column differ significantly $(p<0.05)$.

ences in Lactobacillus and Enterococcus counts were observed for the same time. At $35 \mathrm{~d}$, the LAB supplementation group had higher Lactobacillus counts than the control or YC supplementation groups. The groups receiving either $\mathrm{BA}$ or $\mathrm{BA}+$ LAB supplementation also had increased Lactobacillus counts.

The relative numbers of $L$. agilis and $L$. reuteri in cecal content are shown in Figure 1. The relative numbers of both lactobacilli were significantly affected by BA or LAB supplementation at $35 \mathrm{~d}$. However, none of the treatments had a significant en-

Table 2. Effect of yeast with bacteriocin (BA), Lactobacillus cultures (LAB) and mixture of both supplementations on the growth performance of broiler chickens

\begin{tabular}{|c|c|c|c|c|c|c|c|}
\hline \multirow{2}{*}{ Component } & \multicolumn{5}{|c|}{ Treatment $^{1)}$} & \multirow{2}{*}{ SEM } & \multirow{2}{*}{$p$-value } \\
\hline & Control & YC & BA & LAB & $B A+L A B$ & & \\
\hline \multicolumn{8}{|l|}{$1-21 d$} \\
\hline BWG (g) & 614 & 583 & 580 & 593 & 618 & 15.1 & 0.208 \\
\hline FCR & $1.53^{\mathrm{a}}$ & $1.23^{b}$ & $1.24^{b}$ & $1.39^{\mathrm{ab}}$ & $1.30^{b}$ & 0.068 & 0.018 \\
\hline \multicolumn{8}{|l|}{$22-35 d$} \\
\hline $\mathrm{FCR}$ & 1.57 & 1.59 & 1.54 & 1.52 & 1.70 & 0.011 & 0.681 \\
\hline \multicolumn{8}{|l|}{$1-35 d$} \\
\hline Feed intake (g) & $2,456^{\mathrm{ab}}$ & $2,256^{b}$ & $2,300^{\mathrm{b}}$ & $2,299^{b}$ & $2,592^{\mathrm{a}}$ & 62.8 & 0.044 \\
\hline BWG (g) & $1,593^{b}$ & $1,645^{\mathrm{ab}}$ & $1,713^{a b}$ & $1,712^{\mathrm{ab}}$ & $1,778^{\mathrm{a}}$ & 66.6 & 0.033 \\
\hline FCR & 1.54 & 1.37 & 1.34 & 1.34 & 1.46 & 0.074 & 0.167 \\
\hline
\end{tabular}

SEM, standard error of the mean; BWG, body weight gain; FCR, feed conversion rate (feed/gain).

1) Control, basal diet; YC, yeast control (basal diet $+0.25 \%$ Saccharomyces cerevisiae yeast powder); BA, basal diet $+0.25 \%$ yeast with bacteriocin; $L A B$, basal diet $+L a c t o b a c i l l u s$ cultures; $B A+L A B$, basal diet $+0.25 \%$ yeast with bacteriocin+Lactobacillus cultures.

$a, b$ Means with different superscripts with in the same row differ significantly $(p<0.05)$. 
hancing effect on both lactobacilli at $21 \mathrm{~d}$. The yeast with bacteriocin (BA) supplementation did not significantly affect the relative number of $L$. agilis and $L$. reuteri in cecal content at $21 \mathrm{~d}$, but BA supplementation significantly decreased both lactobacilli numbers at $35 \mathrm{~d}$. The yeast without bacteriocin (yeast control, YC) treatment showed no effect on both lactobacilli numbers in cecal content at $21 \mathrm{~d}$ or $35 \mathrm{~d}$.

\section{Cecal SCFA composition and ammonia concentration}

The results of SCFA and ammonia analysis of the cecal samples are shown in Table 4 . The proportion of propionic acid of cecal samples in $\mathrm{LAB}$ and $\mathrm{BA}+\mathrm{LAB}$ groups were significantly lower than those of the control and BA treatment groups at 21 $d(p<0.05)$. However, the concentration of acetic acid did not differ significantly among the treatment or control groups during the experimental period.

Comparing to the control groups, the combination of $\mathrm{BA}$ and LAB resulted in significant low values of branched SCFA (iso-butyric and iso-valeric acid) at $21 \mathrm{~d}$, but the same effect was not observed at $35 \mathrm{~d}$.

A synergistic effect of $\mathrm{BA}$ and $\mathrm{LAB}$ on decreasing the butyric and valeric acid proportion could be observed at $35 \mathrm{~d}$, but the BA treatment did not have any effect on proportions of butyric and valeric acid at $21 \mathrm{~d}$.

Total SCFA concentration as well as the proportions of propionic acid and branch chain SCFA increased as the broiler chickens aged. The combination of BA and LAB supplementation (BA+LAB treatment) resulted in a higher total SCFA concentration than the $\mathrm{BA}$ or $\mathrm{LAB}$ supplementation group, but the LAB treatment had a significantly lower total SCFA concentration than other treatment groups at $35 \mathrm{~d}(\mathrm{p}<0.05)$. All supplementations in this study tended to decrease the ammonia concentration of cecal samples at $21 \mathrm{~d}$, with the LAB supplementation resulting in the lowest ammonia concentration. However, there was no significant difference of ammonia concentration between any of the groups at $35 \mathrm{~d}$.

\section{Blood biochemical parameters}

Table 5 shows the effect of different treatments on blood biochemical parameters. In an evaluation of hepatic function, ALT activity was not affected by any of the treatments at $21 \mathrm{~d}$ and $35 \mathrm{~d}$. At $21 \mathrm{~d}$, the LAB supplementation resulted in higher AST activity, but a reduction in AST activity was observed in the YC treatment group. A significant treatment effect was found in plasma TG, cholesterol, and LDL-C levels. The BA supplementation alone resulted in a significantly lower TG concentration at $21 \mathrm{~d}$, but the synergistic effect of $\mathrm{BA}$ and $\mathrm{LAB}(\mathrm{BA}+$ $\mathrm{LAB}$ treatment group) was required to reduce the TG concentration at $35 \mathrm{~d}$. However, the synergistic effect of $\mathrm{BA}$ and $\mathrm{LAB}$ was not observed in decreasing the plasma cholesterol level. In comparison to the control group, both $\mathrm{BA}$ and LAB treatments independently resulted in lower plasma cholesterol at $35 \mathrm{~d}$, but showed no effect on plasma cholesterol when combined ( $\mathrm{BA}+\mathrm{LAB}$ treatment). All treatments, except LAB, increased the plasma cholesterol level, with the YC treatment resulting in the highest cholesterol level at 21 and $35 \mathrm{~d}$. The concentration of plasma LDL-C presented the same pattern as the plasma cholesterol level, with the BA supplementation decreasing the

Table 4. Effect of yeast with bacteriocin (BA), Lactobacillus culture (LAB) and mixture of both supplementations on cecal short chain fatty acid (SCFA) and ammonia (NH ${ }_{3}$ ) concentration of broiler chickens

\begin{tabular}{|c|c|c|c|c|c|c|c|c|}
\hline \multirow{2}{*}{ Treatment $t^{2)}$} & \multicolumn{6}{|c|}{ SCFA $^{1)}$ proportion $\%$} & \multirow{2}{*}{$\begin{array}{c}\text { Total SCFA } \\
\mu \mathrm{mol} / \mathrm{g}\end{array}$} & \multirow{2}{*}{$\begin{array}{c}\mathrm{NH}_{3} \\
\mathrm{mg} / \mathrm{g}\end{array}$} \\
\hline & Ac & $\mathrm{Pr}$ & $\mathrm{Bu}$ & Val & isoBu & isoVal & & \\
\hline \multicolumn{9}{|l|}{$21 d$} \\
\hline Control & 81.47 & $6.15^{\mathrm{a}}$ & 11.18 & 0.61 & $0.70^{\mathrm{a}}$ & $0.63^{\mathrm{a}}$ & 100.14 & $0.76^{\mathrm{a}}$ \\
\hline YC & 83.27 & $4.15^{b c}$ & 10.92 & 0.94 & $0.38^{\mathrm{ab}}$ & $0.33^{\mathrm{ab}}$ & 98.05 & $0.72^{2 \mathrm{~b}}$ \\
\hline BA & 84.48 & $5.48^{\mathrm{ab}}$ & 9.99 & 0.44 & $0.67^{\mathrm{a}}$ & $0.38^{\mathrm{ab}}$ & 82.16 & $0.69^{\mathrm{ab}}$ \\
\hline$L A B$ & 77.80 & $3.55^{c}$ & 12.15 & 0.75 & $0.19^{b}$ & $0.28^{\mathrm{ab}}$ & 100.43 & $0.55^{b}$ \\
\hline$B A+L A B$ & 82.10 & $3.50^{c}$ & 11.77 & 0.72 & $0.31^{b}$ & $0.12^{b}$ & 94.27 & $0.59^{\mathrm{ab}}$ \\
\hline SEM & 2.306 & 0.579 & 1.011 & 0.185 & 0.121 & 0.118 & 7.407 & 0.062 \\
\hline p-value & 0.168 & 0.003 & 0.292 & 0.212 & 0.011 & $<0.001$ & 0.204 & 0.042 \\
\hline \multicolumn{9}{|l|}{$35 d$} \\
\hline Control & 73.50 & 12.12 & $10.01^{\mathrm{a}}$ & $1.15^{b}$ & 1.28 & 1.70 & $128.52^{\mathrm{ab}}$ & 0.95 \\
\hline$Y C$ & 75.26 & 11.18 & $9.00^{\mathrm{a}}$ & $1.06^{b}$ & 1.13 & 1.59 & $126.55^{\mathrm{ab}}$ & 0.74 \\
\hline BA & 74.24 & 11.72 & $10.13^{\mathrm{a}}$ & $1.66^{\mathrm{a}}$ & 1.41 & 1.79 & $115.52^{b}$ & 0.80 \\
\hline$L A B$ & 77.52 & 10.28 & $7.47^{\mathrm{ab}}$ & $1.10^{b}$ & 1.30 & 1.51 & $82.84^{c}$ & 0.85 \\
\hline$B A+L A B$ & 78.82 & 11.96 & $4.68^{b}$ & $0.60^{c}$ & 1.13 & 1.30 & $135.47^{\mathrm{a}}$ & 0.79 \\
\hline SEM & 2.499 & 1.417 & 1.301 & 0.133 & 0.136 & 0.508 & 5.938 & 0.121 \\
\hline $\mathrm{p}$-value & 0.319 & 0.197 & 0.032 & $<0.001$ & 0.277 & 0.097 & $<0.001$ & 0.329 \\
\hline
\end{tabular}

${ }^{11} \mathrm{Ac}$, acetic acid; $\mathrm{Pr}$, propionic acid; Bu, butyric acid; Val, valeric acid; isoBu, iso-butyric acid; isoVal, iso-valeric acid.

${ }^{2)}$ Control, basal diet; $Y C$, yeast control (basal diet $+0.25 \%$ Saccharomyces cerevisiae yeast powder); BA, basal diet $+0.25 \%$ yeast with bacteriocin; LAB, basal diet+Lactobacillus cultures; $B A+L A B$, basal diet $+0.25 \%$ yeast with bacteriocin + Lactobacillus cultures $S E M$, standard error of the mean.

$a, b, c$ Means with different superscripts with in the same column differ significantly $(p<0.05)$. 
Table 5. Effect of yeast with bacteriocin (BA), Lactobacillus culture (LAB) and mixture of both supplementations on blood biochemical parameters of broiler chickens

\begin{tabular}{lccccc}
\hline Treatment $^{1)}$ & $\begin{array}{c}\text { ALT } \\
(\mathbf{U} / \mathbf{L})\end{array}$ & $\begin{array}{c}\text { AST } \\
(\mathbf{U} / \mathbf{L})\end{array}$ & $\begin{array}{c}\text { TG } \\
(\mathbf{m g} / \mathbf{d L})\end{array}$ & $\begin{array}{c}\text { Cholesterol } \\
(\mathbf{m g} / \mathbf{d L})\end{array}$ & $\begin{array}{c}\text { LDL-C } \\
(\mathbf{m g} / \mathbf{d L})\end{array}$ \\
\hline 21 d & & & & & \\
Control & 1.84 & $59.58^{\mathrm{ab}}$ & $30.39^{\mathrm{a}}$ & $143.10^{\mathrm{b}}$ & $122.00^{\mathrm{b}}$ \\
YC & 1.24 & $51.79^{\mathrm{b}}$ & $24.04^{\mathrm{ab}}$ & $163.42^{\mathrm{a}}$ & $139.35^{\mathrm{a}}$ \\
BA & 1.74 & $58.09^{\mathrm{ab}}$ & $21.87^{\mathrm{b}}$ & $157.23^{\mathrm{ab}}$ & $138.87^{\mathrm{a}}$ \\
LAB & 1.41 & $64.02^{\mathrm{a}}$ & $28.96^{\mathrm{ab}}$ & $146.79^{\mathrm{b}}$ & $130.19^{\mathrm{ab}}$ \\
BA+LAB & 0.87 & $58.38^{\mathrm{ab}}$ & $28.80^{\mathrm{ab}}$ & $154.97^{\mathrm{ab}}$ & $137.34^{\mathrm{a}}$ \\
SEM & 0.466 & 2.816 & 2.673 & 5.356 & 4.310 \\
p-value & 0.478 & 0.022 & 0.021 & 0.017 & 0.023 \\
35 d & & & & & \\
Control & 1.48 & 51.93 & $24.62^{\mathrm{a}}$ & $134.36^{\mathrm{ab}}$ & $117.02^{\mathrm{ab}}$ \\
YC & 1.53 & 48.23 & $20.15^{\mathrm{ab}}$ & $142.18^{\mathrm{a}}$ & $124.19^{\mathrm{a}}$ \\
BA & 1.26 & 46.85 & $21.39^{\mathrm{ab}}$ & $108.13^{\mathrm{c}}$ & $91.56^{\mathrm{c}}$ \\
LAB & 1.28 & 53.45 & $22.00^{\mathrm{a}}$ & $124.48^{\mathrm{b}}$ & $105.92^{\mathrm{b}}$ \\
BA+LAB & 1.47 & 50.95 & $16.92^{\mathrm{b}}$ & $138.07^{\mathrm{a}}$ & $118.09^{\mathrm{ab}}$ \\
SEM & 0.141 & 3.862 & 1.529 & 4.489 & 4.279 \\
P-value & 0.420 & 0.323 & 0.028 & $<0.001$ & $<0.001$ \\
\hline
\end{tabular}

ALT, alanine aminotransferase; AST, aspartate aminotransferase; TG, triacylglycerol; LDL-C, low density lipoprotein cholesterol.

${ }^{1)}$ Control = basal diet; $Y C=$ yeast control (basal diet $+0.25 \%$ Saccharomyces cerevisiae yeast powder); $B A=$ basal diet $+0.25 \%$ yeast with bacteriocin; $L A B=$ basal diet+Lactobacillus cultures; $B A+L A B=$ basal diet $+0.25 \%$ yeast with bacteriocin $+L a c$ tobacillus cultures; SEM, standard error of the mean.

$a, b, c$ Means with different superscripts with in the same column differ significantly $(p<0.05)$.

cholesterol and LDL-C level significantly at $35 \mathrm{~d}$.

\section{Lactobacilli adhesion assay}

The in vitro lactobacilli adhesion assay results of ileum and cecal samples are presented in Table 6. The BA+LAB treatment increased the adhered lactobacilli proportion in ileum and ceca significantly at $21 \mathrm{~d}$, especially in the ceca. However, it did not significantly enhance the adhesion proportion of lactobacilli of cecal samples at $35 \mathrm{~d}$. The YC supplementation had no effect on increasing the adhered lactobacilli proportion of ileum and

Table 6. Effect of yeast with bacteriocin (BA), Lactobacillus culture (LAB) and mixture of both supplementations on lactobacilli adhesion ability of broiler chickens

\begin{tabular}{lcccc}
\hline \multirow{2}{*}{ Treatment $^{1)}$} & \multicolumn{2}{c}{$21 \mathrm{~d}$} & \multicolumn{2}{c}{$35 \mathrm{~d}$} \\
\cline { 2 - 5 } & lleum & Ceca & Ileum & Ceca \\
\hline Control & $56.06^{\mathrm{ab}}$ & $54.26^{\mathrm{b}}$ & $34.59^{\mathrm{c}}$ & $71.31^{\mathrm{ab}}$ \\
YC & $45.58^{\mathrm{b}}$ & $53.96^{\mathrm{b}}$ & $65.57^{\mathrm{a}}$ & $65.28^{\mathrm{b}}$ \\
BA & $54.29^{\mathrm{ab}}$ & $43.12^{\mathrm{b}}$ & $43.82^{\mathrm{bc}}$ & $77.26^{\mathrm{a}}$ \\
LAB & $58.30^{\mathrm{ab}}$ & $46.42^{\mathrm{b}}$ & $51.16^{\mathrm{ab}}$ & $77.99^{\mathrm{a}}$ \\
BA+LAB & $67.71^{\mathrm{a}}$ & $81.70^{\mathrm{a}}$ & $55.60^{\mathrm{ab}}$ & $76.26^{\mathrm{ab}}$ \\
SEM & 4.808 & 8.148 & 4.973 & 3.657 \\
p-value & 0.036 & 0.037 & 0.019 & 0.017 \\
\hline
\end{tabular}

${ }^{1)}$ Control, basal diet; $Y C$, yeast control (basal diet $+0.25 \%$ Saccharomyces cerevisiae yeast powder); $B A$, basal diet $+0.25 \%$ yeast with bacteriocin; $L A B$, basal diet+Lactobacillus cultures; $B A+L A B$, basal diet $+0.25 \%$ yeast with bacteriocin+Lactobacillus cultures; SEM, standard error of the mean.

$a, b, c$ Means with different superscripts with in the same column differ significantly $(p<0.05)$. cecal samples at $21 \mathrm{~d}$ and decrease the cecal adhesion proportion of lactobacilli at $35 \mathrm{~d}$. However, the YC supplementation resulted in the highest adhesion proportion of lactobacilli in ileum at $35 \mathrm{~d}$. In general, the adhered lactobacilli proportion of ileum decreased with increasing chicken age, but the adhered lactobacilli proportion of ceca increased as chicken age increased.

\section{DISCUSSION}

\section{Growth performance}

The results of BWG analysis indicated that BA+LAB supplementation showed the better growth performance than the control group during the overall experimental period. However, all supplementations in this study trended to improve the FCR. Patterson and Burkholder [1] indicated that animal efficacy for most probiotics could be supplemented with an intake of about $10^{8}$ to $10^{9} \mathrm{CFU} / \mathrm{d}$, but over-supplementation had no benefit on growth performance or FCR. Taheri et al [13] reported that the combination of Lactobacillus spp. could positively affect BW. Previous studies also indicated that the functionality of multi-strain probiotics could be more effective and more consistent than that of mono-strain probiotics [14]. Different strains with different characteristics may create probiotic niches, improving chances of successful colonization of other strains through reduction of antagonistic activity of endogenous microbiota against other sensitive probiotic strains and induction of optimal $\mathrm{pH}$ range [15].

$\mathrm{LAB}$ was supplemented in an effective range $\left(10^{7} \mathrm{CFU}\right.$ per gram diet) according to the $\mathrm{LAB}$ supplementation concentration and feed intake of broiler chickens in previous studies $[13,15,16]$. However, the LAB supplementation treatment had no significantly positive effect on broiler growth performance in this study. It is possible that probiotic efficacy may depend on factors including microbial species composition (single or multi-strain mixture) and viability, supplementation level, application method, frequency of application, overall diet, bird age, overall farm hygiene, and environmental stress factors [15]. This suggests that multi-strain lactobacilli mixture composition might be a major concern in probiotic supplementation. The BA product applied in this study was a yeast with bacteriocin; it has been shown to be a broiler growth promoter owing to its ability to enhance the lactic acid bacteria growth in digestive tract and antibiotic activity [8]. In a broiler model, dietary supplementation with $0.15 \%$ to $0.3 \%$ S. cerevisiae resulted in a growth performance equal to that observed with antibiotic supplementation, and broiler chickens with yeast supplementation had better growth and carcass weight than control broilers [17]. In this study, the BWG of BA+LAB supplemented broiler chickens showed better growth performance than other treatment groups during the grower phase. Therefore, we speculate that the better growth performance owing to the BA supplementation might be the result of the combined effect of whole 
yeast cells and albusin B.

\section{Cecal microbial population}

The cecal flora assay results shown in Table 3 and Figure 1 indicate that the YC treatment had no effect on lactic acid bacteria and Enterococcus counts, but it increased the anaerobe number at $21 \mathrm{~d}$, compared to that of the control group. Previous data from Baurhoo et al [18] reported that lactobacilli concentrations did not differ when broiler chickens were fed different levels of yeast supplement or a control diet. It also suggested that yeast cell wall supplementation could increase the cecal Bifidobacteria concentration in hens, but had no effect on the lactobacilli concentration. Angelakis and Raoult [19] indicated that supplementation of a probiotic formula containing $L$. reuteri and other lactic acid bacteria, when used for $40 \mathrm{~d}$ in chickens, reduced the number of Enterobacteriaceae, but the number of lactobacilli and enterococci remained stable. The LAB treatment in this study only enhanced the $L$. agilis and $L$. reuteri growth at $35 \mathrm{~d}$. However, the LAB supplementation in the present study still increased the lactic acid bacteria counts and enhanced the supplemented strains growth in chicken ceca significantly. This suggests that LAB supplementation could modify the lactic acid bacteria composition in the intestine of

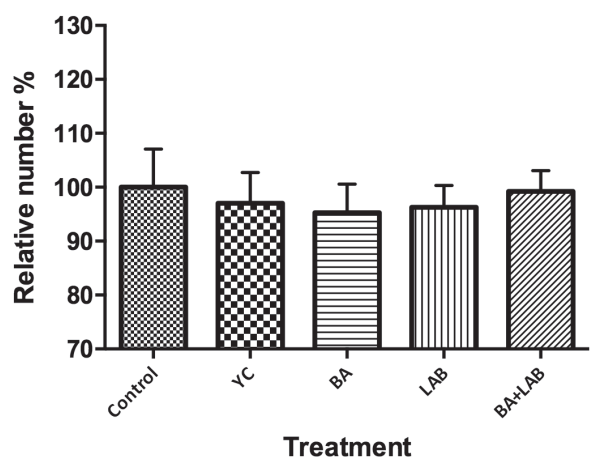

L. agilis ( 35 days)

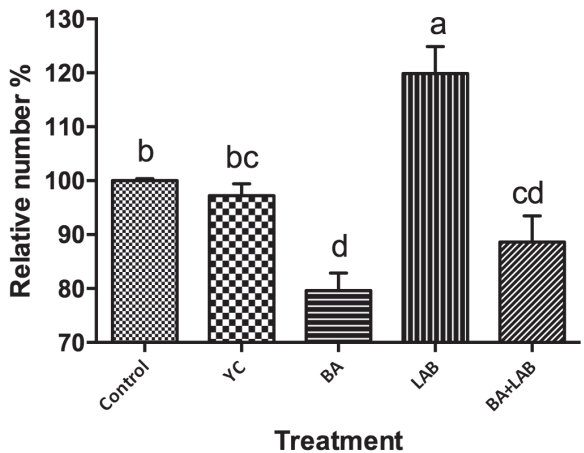

mature chickens.

Previous studies also indicated that the lactobacilli composition in the intestine of mature chickens might reach their highest numbers so that the supplementation strains might contribute to their presence in intestinal microbiota, but probiotic supplementation had the benefit of increasing the abundance and prevalence of Lactobacillus spp. inhabiting the intestine [3]. Other studies using multi-strain-single species as well as multi-strain-multispecies probiotics have shown no significant changes in the gut microflora profile of broiler chickens [20]. At $35 \mathrm{~d}$, supplement diets containing BA with or without LAB resulted in significantly decreased supplementation strains ( $L$. agilis and $L$. reuteri). However, no significant inhibition ability of BA to supplementation strain was observed at $21 \mathrm{~d}$. A lack of response to the supplementation of probiotic might indicate that the control chickens were sufficiently colonized to prevent determination of any real beneficial effects of the treatments [21]. Previous study reported that bacitracin administration suppressed the intestinal colonization of $L$. reuteri in turkeys [21]. Jin et al [22] also reported that the addition of the adherent Lactobacillus culture failed to significantly increase the number of lactobacilli in the ceca of chicken. This suggests that the susceptibility of $L$. reuteri and L. agilis to BA is noted in the
L. returi (21 days)

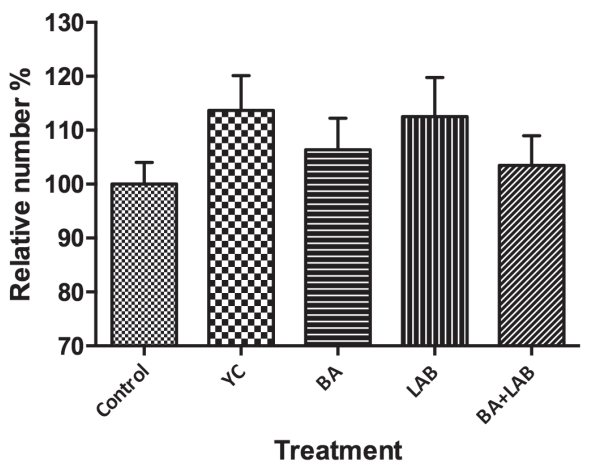

L. returi (35 days)

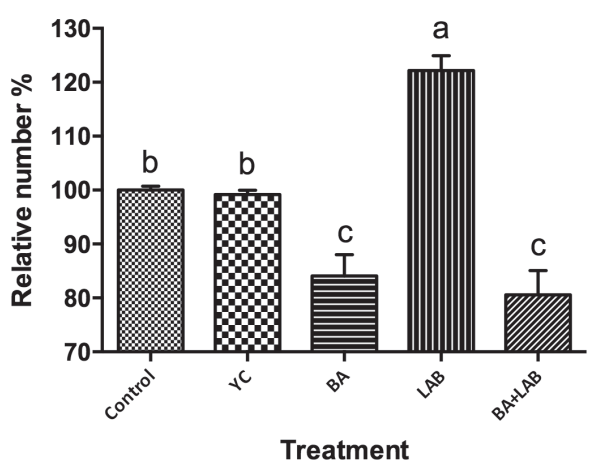

Figure 1. Effect of yeast with bacteriocin and Lactobacillus cultures on cecal L. agilis and L. returi relative number of broiler chickens at $21 \mathrm{~d}$ and $35 \mathrm{~d}$. Bars represent means $\pm S D$, bars with different letters differ significantly $(p<0.05$ ). Control, basal diet; $Y C$, yeast control (basal diet $+0.25 \%$ Saccharomyces cerevisiae yeast powder); $B A$, basal diet $+0.25 \%$ yeast with bacteriocin; $L A B$, basal diet+Lactobacillus cultures; $B A+L A B$, basal diet $+0.25 \%$ yeast with bacteriocin+Lactobacillus cultures. 
BA supplementation treatment, and additional studies on the interaction between BA and supplemented probiotics are required.

\section{Cecal SCFA composition and ammonia concentration}

In the hindgut, the non-digested carbohydrate is fermented by the microflora to produce large quantities of SCFA readily absorbed by the colonic mucosa. Fleming and Gill [23] reported that SCFA play a key role as energy sources, with butyric acid being the most quickly oxidized to $\mathrm{CO}_{2}$.

The significantly low molar proportion of butyric acid in cecal sample was shown in $\mathrm{BA}+\mathrm{LAB}$ treatment groups at $35 \mathrm{~d}$, but the $\mathrm{LAB}$ treatment only tended to decrease the butyric acid. This might be a result from the variation of butyric acid-producing bacteria in the ceca. Previous studies indicated that probiotic stimulated the proliferation of butyric acid-producing bacteria by the mechanism of cross feeding [16]. Some butyric acid-producing bacteria also play a role in acetate and lactate utilization in the ceca [24]. The BA supplement in this study had an antibiotic ability to some ceca flora, and an effect in the proliferation of supplementation probiotic strains. It is possible that BA supplementation would affect the population of lactic acid bacteria in the ceca, and furthermore, effect the proliferation of butyric acid-producing bacteria. Lower total SCFA concentration was observed in the LAB treatment group at 35 $\mathrm{d}$, but $\mathrm{BA}+\mathrm{LAB}$ supplementation resulted in the highest total SCFA concentration among all treatment groups. The effect of probiotic supplementation on cecal SCFA concentration was not consistent; multi-strain-single species or multi-strainmultispecies [20] probiotic supplementation had shown no significant changes in cecal SCFA. However, other studies indicated that probiotic supplementation increased the total SCFA in the ceca of broiler chickens [22]. This suggests that the optimal probiotic concentration is not straightforward; it depends on broiler chicken age, probiotic strain, feed source, and interactions between the probiotic and other feed additives.

In the present study, lower ammonia concentration was observed in $\mathrm{LAB}$ and $\mathrm{BA}+\mathrm{LAB}$ treatment groups at $21 \mathrm{~d}$. A lower proportion of branch-chain SCFAs was also observed in these treatment groups. Casadei et al [25] indicated that low molar proportion of iso-butyric and iso-valeric acid revealed reduced deamination and decarboxylation of amino acids, supporting the decreased proteolysis shown by the ammonia production data. Because energy is the limiting factor for microbial metabolism in the hindgut, once bacteria utilize all pools of readily fermentable starches and carbohydrates, fermentations become increasingly proteolytic, resulting in overproduction of ammonia and noxious amines [24].

Casadei et al [25] reported that the higher the production and absorption of ammonia, the higher is the $\mathrm{pH}$ of the local environment. The decreased cecal ammonia level observed in this study could be attributed to the suppression of ammonia production in the intestine, or to accelerated ammonia absorption from the intestine.

\section{Blood biochemistry}

Serum ALT and AST are parameters for liver damage evaluation. No significant difference was shown in ALT or AST level between control group and each treatment group in this study. It indicated that the treatment supplementation had no negative effect on liver health. All treatments had a decreasing effect on the concentration of TG, with the BA and BA+LAB supplementation groups having the lowest TG levels at $21 \mathrm{~d}$ and $35 \mathrm{~d}$, respectively. There is increasing evidence that probiotics and their cell components modulate the metabolic process of the host, including lipid metabolism [26]. Our previous study on BA supplementation also indicated that the BA modulated the lipid metabolism and resulted in the lower TG levels of broiler chickens [9]. Compared to the control group, the broiler chickens fed with YC showed no effect on TG levels, suggesting that the BA supplementation effect on TG levels was not caused by the yeast host.

LAB supplementation failed to significantly decrease the level of serum cholesterol in this study. In studies of modulating cholesterol metabolism, adding a mixture of lactic acid bacteria culture to broiler chickens' feed resulted in lower cholesterol and LDL-C concentration. However, other broiler chicken feeding studies reported no significant difference of serum cholesterol levels between probiotic supplementation and control groups [2]. The inconsistent results of probiotic supplementation may be because of the difference of suitable living bacteria number, animal age, and supplementation strains. Mansoub [27] indicated that higher Lactobacillus mono-strain culture supplementation (1\%) was beneficial in decreasing serum cholesterol level. However, Kalavathy et al [2] reported that multi-strain Lactobacillus culture (mixed 12 Lactobacillus strains) supplementation higher than $0.1 \%$ could result in a hypocholesterolemic effect. Serum cholesterol levels were significantly lower in broiler chickens fed with diets containing Lactobacillus cultures at $35 \mathrm{~d}$ of age, but the hypocholesterolemic effect was not observed in $10 \mathrm{~d}$ of age [28]. It is speculated that Lactobacillus reduces the cholesterol in the blood by deconjugating bile salts in the intestine, thereby preventing them from acting as precursors in cholesterol synthesis [29]. The Lactobacillus was also found to have a high bile salt hydrolytic activity, which is responsible for deconjugation of bile salts [29].

The BA supplementation improved the counts of lactic acid bacteria in this study, and the hypocholesterolemic effect of BA might be attributed to the enhanced effect of lactic acid bacteria. Our previous study found that BA supplementation could modulate the lipid metabolism of broiler chickens, and that BA increased endogenous cholesterol synthesis and recruited cholesterol from peripheral tissue to the liver [9]. However, there was no significant difference in serum cholesterol or LDL- 
$\mathrm{C}$ levels between the control and $\mathrm{BA}+\mathrm{LAB}$ treatment groups. A partial explanation for this may be that $\mathrm{BA}$ enhances the growth of lactic acid bacteria, but some lactic acid bacteria are also inhibited by albusin B. In this study, BA supplementation significantly decreased the L. agilis and L. returi counts at $35 \mathrm{~d}$ of age (Figure 1). Furthermore, the L. returi supplemented in this study also had the ability to produce reuterin and modulated the flora composition. Therefore, the composition of dominant lactic acid bacteria might be changed under $\mathrm{BA}+\mathrm{LAB}$ treatment, resulting in different antimicrobial metabolites produced by lactic acid bacteria. These different modulation patterns of cholesterol and TG metabolism from other studies implied a more complicated effect of $\mathrm{BA}+\mathrm{LAB}$, more than the contribution of lactic acid bacteria growth promoter or flora composition regulation.

\section{Lactobacilli adhesion}

The beneficial effects of Lactobacillus cultures on broiler chicken performance are probably the result of their strong ability to attach to the chicken intestine, their antagonism towards pathogenic bacteria, and the ability to competitively exclude some pathogenic bacteria [28].

The significantly higher lactic acid bacteria adhesion proportion of $\mathrm{BA}+\mathrm{LAB}$ treatment group at $21 \mathrm{~d}$ of age (Table 6) suggested that $B A$ and $L A B$ had synergistic effects on the attachment ability of lactic acid bacteria. As adhesion may lead to a prolonged residence of probiotic bacteria in the intestinal tract, such property was also considered a potential virulence factor involved in the translocation of pathogens across the mucosal surface [28]. Karimi et al [26] indicated that probiotics stimulate the immunity of the chickens in two ways: i) flora from probiotic migrate throughout the gut wall and multiply to a limited extent, or ii) antigen released by the dead organisms are absorbed and thus stimulate the immune system. The higher adhesion ability of lactic acid bacteria resulted in the prolonger immunity stimulation effect that might improve the broiler health through a better immune status. The colonization of lactic acid bacteria in the broiler intestinal tract appears to have a beneficial effect. The benefit appears to be associated with the production of bacteriocins of some species and by reuterin (a metabolic product secreted by $L$. reuteri), which support competitive exclusion of harmful and pathogenic microorganisms [5].

The BA supplement in this study also showed bacteriocin activity [8], suggesting that BA supplementation contributes to the inhibition of pathogenic microorganisms and supports lactic acid bacteria in competitive exclusion mechanism. The YC treatment group resulted in the higher lactic acid bacteria attachment in the ileum at $35 \mathrm{~d}$. However, YC supplementation had no effect on enhancing the adhesion ability of lactic acid bacteria in the ceca. This can be explained by assuming that the flora composition might be affected by the antagonis- tic characteristics of yeasts. Antagonism of microorganisms by yeasts has been attributed to competition for nutrients and secretion of antibacterial compounds and release of antimicrobial compounds such as killer toxins or "mycocins" [30].

In conclusion, this study demonstrated that the $\mathrm{BA}+\mathrm{LAB}$ supplementation was beneficial to BWG of broiler chickens. Although BA or LAB supplementation showed some advantage on the counts of lactic acid bacteria in ceca at $35 \mathrm{~d}$, BA supplementation had an inhibitory effect on the LAB supplementation strains (L. returi and L. agilis) in this study at $35 \mathrm{~d}$. The results of blood biochemistry and lactic acid bacteria adhesion assays implied that both BA and LAB supplementation were associated with lipid metabolism and immune regulation of broiler. Furthermore, the effect of BA and LAB supplementation may result from enhancing the lactic acid bacterial growth and physiological characterization of bacteriocin. However, further research is required to determine the effect of BA on common probiotic strains, especially the interaction between the enhancing and inhibiting mechanisms of lactic acid bacteria.

\section{CONFLICT OF INTEREST}

We certify that there is no conflict of interest with any financial organization regarding the material discussed in the manuscript.

\section{ACKNOWLEDGMENTS}

This work was supported by Council of Agriculture, Executive Yuan R.O.C. (99-AS-2.1.3-AD-U1).

\section{REFERENCES}

1. Patterson JA, Burkholder KM. Application of prebiotics and probiotics in poultry production. Poult Sci 2003;82:627-31.

2. Kalavathy R, Abdullah N, Jalaludin S, et al. Effects of Lactobacillus cultures on growth performance, abdominal fat deposition, serum lipids and weight of organs of broiler chickens. Br Poult Sci 2003; 44:139-44.

3. Lan PT, Binh le T, Benno Y. Impact of two probiotic Lactobacillus strains feeding on fecal lactobacilli and weight gains in chicken. J Gen Appl Microbiol 2003;49:29-36.

4. Talarico TL, Dobrogosz WJ. Chemical characterization of an antimicrobial substance produced by Lactobacillus reuteri. Antimicrob Agents Chemother 1989;33:674-9.

5. Edens FW, Parkhurst CR, Casas IA, et al. Principles of ex ovo competitive exclusion and in ovo administration of Lactobacillus reuteri. Poult Sci 1997;76:179-96.

6. Dobrogosz WJ, Casas IA, Pagano GA, et al. Lactobacillus reuteri and the enteric microbiota. In: Gruff R, Medtvedt T, Norin E, editors. The regulatory and protective role of the normal microflora. London, UK: MacMillian Press Ltd; 1989. p. 283-92.

7. Servin AL, Coconnier MH. Adhesion of probiotic strains to the 
intestinal mucosa and interaction with pathogens. Best Pract Res Clin Gastroenterol 2003;17:741-54.

8. Wang HT, Yu C, Hsieh YH, et al. Effects of albusin B (a bacteriocin) of Ruminococcus albus 7 expressed by yeast on growth performance and intestinal absorption of broiler chickens - its potential role as an alternative to feed antibiotics. J Sci Food Agric 2011;91:233843.

9. Wang HT, Li YH, Chou IP, et al. Albusin B modulates lipid metabolism and increases antioxidant defense in the broiler chickens by a proteomic approach. J Sci Food Agric 2013;93:284-92.

10. Abdulrahim SM, Haddadin MS, Odetallah NH, et al. Effect of Lactobacillus acidophilus and zinc bacitracin as dietary additives for broiler chickens. Br Poult Sci 1999;40:91-4.

11. Committee on Nutrient Requirements of Poultry, National Research Council. Nutrient requirements of poultry. 9th ed. Washington, DC: National Academy Press; 1994.

12. SAS. SAS user's guide: Statistics, 9.2 ed. Cary, NC: SAS Inst. Inc.; 2003.

13. Taheri HR, Moravej H, Tabandeh F, et al. Efficacy of combined or single use of Lactobacillus crispatus LT116 and L. johnsonii LT171 on broiler performance. Br Poult Sci 2010;51:580-5.

14. Timmerman HM, Koning CJ, Mulder L, et al. Monostrain, multistrain and multispecies probiotics - A comparison of functionality and efficacy. Int J Food Microbiol 2004;96:219-33.

15. Zhang ZF, Kim IH. Effects of multistrain probiotics on growth performance, apparent ileal nutrient digestibility, blood characteristics, cecal microbial shedding, and excreta odor contents in broilers. Poult Sci 2014;93:364-70.

16. Meimandipour A, Shuhaimi M, Soleimani AF, et al. Selected microbial groups and short-chain fatty acids profile in a simulated chicken cecum supplemented with two strains of Lactobacillus. Poult Sci 2010;89:470-6.

17. Onifade AA, Odunsi AA, Babatunde GM, et al. Comparison of the supplemental effects of Saccharomyces cerevisiae and antibiotics in low-protein and high-fiber diets fed to broiler chickens. Arch Tierernahr 1999;52:29-39.

18. Baurhoo B, Ferket PR, Zhao X. Effects of diets containing different concentrations of mannanoligosaccharide or antibiotics on growth performance, intestinal development, cecal and litter microbial populations, and carcass parameters of broilers. Poult Sci 2009; 88:2262-72.
19. Angelakis E, Raoult D. The increase of Lactobacillus species in the gut flora of newborn broiler chicks and ducks is associated with weight gain. PLoS One. 2010;5:e10463.

20. Priyankarage N, Silva S, Gunaratne S, et al. Efficacy of probiotics and their effects on performance, carcass characteristics, intestinal microflora and Salmonella incidence in broilers [Abstract]. Br Poult Sci 2003;44(Suppl 1):26-7.

21. England JA,Watkins SE, Saleh E. Effects of Lactobacillus reuteri on live performance and intestinal development of male turkeys. J Appl Poult Res 1996;5:311-24.

22. Jin LZ, Ho YW, Abdullah N, et al. Effects of adherent Lactobacillus cultures on growth, weight of organs and intestinal microflora and volatile fatty acids in broilers. Anim Feed Sci Technol. 1998; 70: 197-209.

23. Fleming SE, Gill R. Aging stimulates fatty acid oxidation in rat colonocytes but does not influence the response to dietary fiber. J Gerontol A Biol Sci Med Sci 1997;52:B318-30.

24. Bjerrum L, Engberg RM, Leser TD, et al. Microbial community composition of the ileum and cecum of broiler chickens as revealed by molecular and culture-based techniques. Poult Sci 2006;85: 1151-64.

25. Casadei G, Grilli E, Piva A. Pediocin A modulates intestinal microflora metabolism in swine in vitro intestinal fermentations. J Anim Sci 2009;87:2020-8.

26. Karimi TMA, Moghaddam AR, Rahimi SH, et al. Assessing the effect of administering probiotics in water or as a feed supplement on broiler performance and immune response. Br Poult Sci 2010; 51: 178-84.

27. Mansoub NH. Effect of probiotic bacteria utilization on serum cholesterol and triglycerides contents and performance of broiler chickens. Global Vet 2010;5:184-6.

28. Jin LZ, Ho YW, Ali AM, et al. Effect of adherent Lactobacillus spp. on in vitro adherence of salmonellae to the intestinal epithelial cells of chickens. J Appl Bacteriol 1996;81:201-6.

29. Alkhalf A, Alhaj M, Al-Homidan I. Influence of probiotic supplementation on blood parameters and growth performance in broiler chickens. Saudi J Biol Sci 2010;17:219-25.

30. Hatoum R, Labrie S, Fliss I. Antimicrobial and probiotic properties of yeasts: from fundamental to novel applications. Front Microbiol 2012;3:421. 